\title{
Surface and Volume Variation Determination of Laguna de Laja (Chile) since 2007
}

\author{
Esteban Fernandez a, Guido Staub a,* \\ a University of Concepción, Department for Geodetic Sciences and geomatics, Juan Antonio Coloma 0201,Los Ángeles, Chile, \\ esfernandez@udec.cl,gstaub@udec.cl \\ * Corresponding author
}

Keywords: Satellite Imagery, Bathymetry, NDWI

\begin{abstract}
:
The present work aims to determine surface and volume variations of Laguna de Laja using satellite imagery (Landsat), image processing techniques, a digital bathymetric model and in situ measurements. Laguna de Laja, one of the mayor hydrologic resources in Chile is located at about $600 \mathrm{~km}$ to the south of Santiago de Chile, Chiles capital city, in the Andes mountains. Its particularity is caused by

1. Tourism - as it is located in the vicinity of the Laguna de Laja National Park

2. Irrigation - 120000 hectares

3. Hydroelectric power generation - 4 mayor power plants

For this study, Landsat 5, 7 and 8 were considered. A total of 47 satellite images were acquired for March, June, September and December since 2007.

The bathymetric model of the Laguna de Laja was generated in 2001 in a scientific research collaboration between the University of Concepción (Chile) and the German Research Center for Environmental Research (Germany). A single beam echo sounder EA400 in combination with a Trimble GPS 4000 SSi receiver was used to survey the Laguna de Laja.

One of the fundamental steps on which is based our approach makes use of the Normalized Difference Water Index (NDWI), which considers the green and near infrared bands of Landsat. The calculation of this index allows to separate water bodies from any other type of surface coverage (McFeeters, 1996). In our case the Laguna de Laja has a quite irregular form but it is embedded in a mountainous area. In consequence it can easily be detected by the generation of density slices based on NDWI.

Our results indicate that the Laguna de Laja suffers a permanent loss of water. Nevertheless there is no linear trend observable. Between 2010 and 2013, a constant loss in both surface ( 2 cukm) and volume (32 sqkm) can be detected. Furthermore, between 2014 and 2016, water volume increased in both surface and volume. Since 2017 seasonal maxima (December) and minima (June) are clearly defined and almost no loss has occurred since. In totaled considering the observed time span surface diminished by $20,3 \%$ and water volume loss is $24,5 \%$.
\end{abstract}

Future work has to be focused on the sources for the indicated loss of water. Many reasons, such as higher temperatures, increase in water usage for irrigation, decrease of precipitation, and many others. 